BMJ Open

Diabetes

Research

\& Care

\section{Incidence and seasonality of type 1 diabetes: a population-based 3-year cohort study using the National Database in Japan}

To cite: Nishioka Y, Noda T, Okada S, et al. Incidence and seasonality of type 1 diabetes: a population-based 3 -year cohort study using the National Database in Japan. BMJ Open Diab Res Care 2020;8:e001262. doi:10.1136/ bmjdrc-2020-001262

- Supplemental material is published online only. To view please visit the journal online (http://dx. doi.org/10.1136/ bmjdrc-2020-001262).

Received 7 February 2020 Revised 16 May 2020 Accepted 6 June 2020

\section{Check for updates}

(C) Author(s) (or their employer(s)) 2020. Re-use permitted under CC BY-NC. No commercial re-use. See rights and permissions. Published by BMJ.

${ }^{1}$ Department of Public Health, Health Management and Policy, Nara Medical University, Kashihara, Nara, Japan ${ }^{2}$ Department of Diabetes and Endocrinology, Nara Medical University, Kashihara, Nara, Japan

${ }^{3}$ Healthcare and Wellness Division, Mitsubishi Research Institute, Inc, Tokyo, Japan

Correspondence to Dr Tatsuya Noda; noda@naramed-u.ac.jp

\section{ABSTRACT}

Introduction To investigate the incidence of type 1 diabetes by age group $(0-19,20-39,40-59, \geq 60$ years) in Japan and whether there is seasonality in this incidence. Research design and methods The incidence of type 1 diabetes from September 2014 to August 2017 was estimated using 2013-2018 data from the National Database of Health Insurance Claims and Specific Health Check-ups of Japan. The incidence rate was analyzed using Tango's Index and the self-controlled case series method.

Results Overall, 10400 of the 79175553 included individuals were diagnosed with type 1 diabetes. The incidence of type 1 diabetes from September 2014 to August 2017 was 4.42/100 000 person-years. The incidence rates for men aged $0-19,20-39,40-59$, and $\geq 60$ years were $3.94,5.57,5.70$, and 3.48 , respectively. Among women, the incidence rates for the same age ranges were $5.22,4.83,4.99$, and 3.31 , respectively. Tango's index showed that the incidence rate of type 1 diabetes was significantly associated with seasons among those aged 0-19 years. Further, the self-controlled case series method showed a significant interaction between age and season, with the incidence of type 1 diabetes being higher in spring for patients younger than 20 years of age.

Conclusions In Japan, men aged 40-59 years and women aged 0-19 years are the groups with the highest incidence of type 1 diabetes. Further, the incidence of younger-onset diabetes in Japan was higher in spring (from March to May).

\section{INTRODUCTION}

Type 1 diabetes is usually the result of immunemediated $\beta$-cell destruction, characterized by absolute insulin deficiency. ${ }^{1}$ Seasonal tendencies in the onset of type 1 diabetes have been reported in some countries, ${ }^{2-7}$ but appear to be exclusive to countries with a higher incidence of type 1 diabetes. ${ }^{8-10}$ In general, there is no consensus on the seasonality of onset of type 1 diabetes.

The National Database of Health Insurance Claims and Specific Health Check-ups

\section{Significance of this study}

What is already known about this subject?

- In general, there is no consensus on the seasonality of onset of type 1 diabetes.

What are the new findings?

- The incidence of type 1 diabetes from September 2014 to August 2017 was 4.42/100 000 person-years.

- The incidence rate of type 1 diabetes was significantly associated with seasons among those aged $0-19$ years.

- There is a significant interaction between age and season, with the incidence of type 1 diabetes being higher in spring for patients younger than 20 years of age.

How might these results change the focus of research or clinical practice?

- In Japan, the incidence of younger-onset diabetes in Japan was higher in spring (from March to May). The results may indicate that childhood-onset type 1 diabetes and adult type 1 diabetes have different modes of onset.

of Japan (NDB) is a comprehensive database of health insurance claims covered by the Japanese National Health Insurance system. The NDB is one of the world's largest healthrelated databases and contains complete datasets of medical care received by insured inpatients and outpatients. The NDB has an extremely large study population that enables observation of a sufficient number of individuals with relatively rare medical conditions. Thus, several studies have provided real-world evidence using the NDB. ${ }^{11-14}$

This study aimed to identify the incidence rate of type 1 diabetes with respect to age and seasons in Japan. 


\section{METHODS}

\section{Study design and population}

The present study was a population-based, real-world, retrospective study conducted using the NDB dataset. The cohort comprised individuals enrolled in the NDB. Japan has a universal health coverage system for its 127 million citizens, and the NDB includes all patients using any type of insurance program. The NDB data provide information on personal identifier (ID0 variable $)^{15}$, date, age group, sex, description of the procedures performed, International Classification of Diseases (ICD-10) diagnosis codes, medical care received, medical examinations conducted that did not have results, and prescribed drugs independent of the doctor's or patient's reports. Drug information includes prescription amount, brand name, generic name, dosage, and number of days prescribed. In this study, we defined a person's age as the age at the last insurance use. We designed the study cohort such that data of all patients from the NDB dataset (collected between April 2013 and March 2018) were included in the analysis. The need for informed consent was waived owing to the retrospective nature of the study. All patient data were anonymized prior to analysis.

\section{Definition of type 1 diabetes}

Patients with newly diagnosed type 1 diabetes were defined as those diagnosed with type 1 diabetes starting from September 2014, who were prescribed insulin and instructed to self-monitor their blood glucose. Patients already prescribed a diabetes drug between April 2013 and August 2014 were classified to have existing diabetes and were excluded from the analysis. Patients with gestational diabetes were treated with caution because insulin may have been prescribed before the onset of type 1 diabetes. For patients with ICD-10 codes for both type 1 diabetes and gestational diabetes, the incidence date of type 1 diabetes was defined as the date when the diagnosis code for type 1 diabetes was recorded. For patients with only the diagnosis code of type 1 diabetes, we defined their incidence date of type 1 diabetes as the first day of being prescribed insulin. The codes used for analysis are shown in online supplemental tables $1-4$.

\section{Statistical analysis}

In this study, we included people who used health insurance in the following two periods: April 2013August 2014 and September 2017-March 2018. The population at risk of type 1 diabetes was defined as those who used health insurance from September 2014 to August 2017 or until their first diabetic drug was prescribed during the study period. The incidence of type 1 diabetes was determined for every season as defined by the Japanese Meteorological Agency (fall (autumn): September to November; winter: December to February; spring: March to May; and summer: June to August). ${ }^{16}$ The existence of time clustering was evaluated using Tango statistics. ${ }^{17}$

If time clustering was found, we estimated the incidence ratio for type 1 diabetes using the season with the highest incidence rate as reference. We calculated the incidence rate ratio of the risk season to the control seasons using a self-controlled case series method (generalized estimation equation Poisson model) ${ }^{18}{ }^{19}$ (online supplemental figure). Type 1 diabetes (outcome) does not occur more than once per person, and the model accounted for the multiple risk season (exposure). Because the observation period was 3 years, patients experienced risk seasons three times and control seasons nine times. Independent variables in the model included age ranges $(0-19,20-39,40-59, \geq 60$ years $)$, sex, years after observation $(0,1$, or 2$)$, the seasonal categories (season with highest incidence, others), and interaction

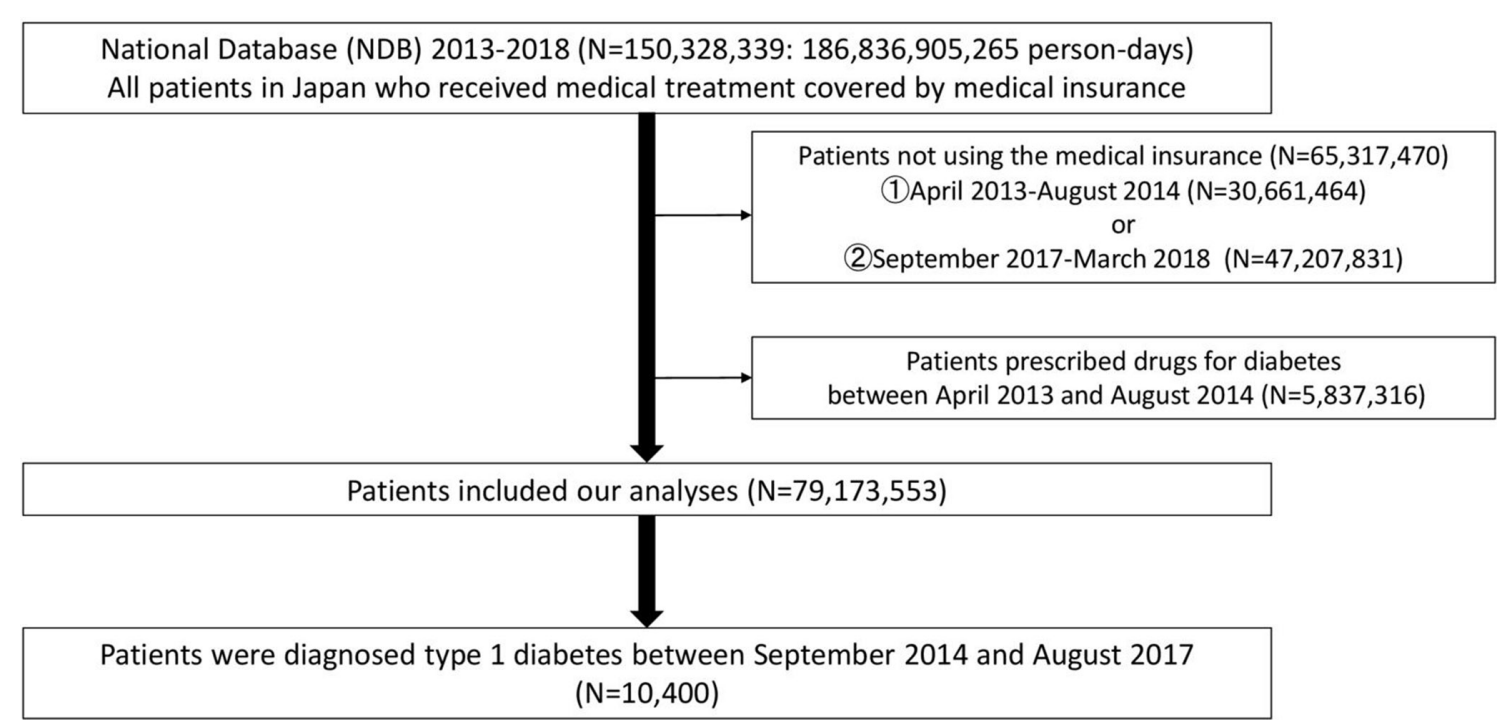

Figure 1 Flowchart of the study. 
between age ranges and seasonal categories. All statistical tests were two-tailed, and $\mathrm{p}<0.05$ were considered significant. All statistical analyses were performed using Microsoft SQL Server 2016 Standard (Microsoft, Redmond, Washington, USA) and IBM SPSS for Windows, V.25.0 (IBM, Armonk, New York, USA).

\section{Quantification of outcome misclassification}

We also performed a validation study to quantify the misclassification of type 1 diabetes definition. A previous study reported that data from electronic health records can be used to accurately identify patients with type 1 diabetes among patients with diabetes (including type 1 , type 2 , and so on)..$^{20}$ For performing this validation study, we included all patients in the NDB who were at risk of type 1 diabetes on September 2014 and who had received diabetic medication more than once from September 2014 to August 2017 (diabetic medication codes are shown in online supplemental tables 1-3). Sample size calculation was based on a prevalence of $1 \%$ for type 1 diabetes and on an absolute accuracy of $1 \%$ (ie, 1000000 individuals), aiming to calculate the

\section{Female $/ 100,000$ person-year}

10

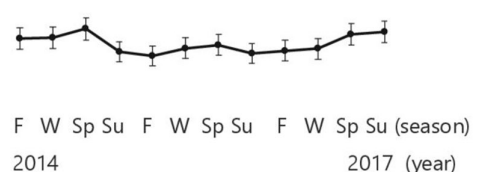

0

10

$00-19 y \quad 5$

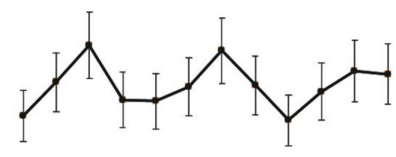

0

10

20-39y

5

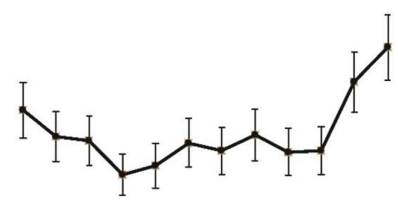

0

10

40-59y 5

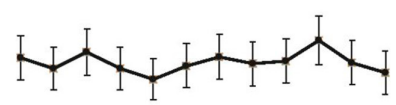

0

$60-y \quad 5$

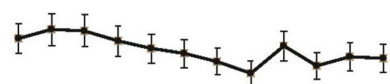

Male

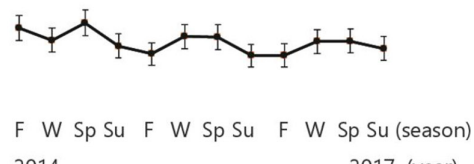

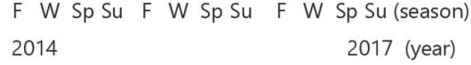
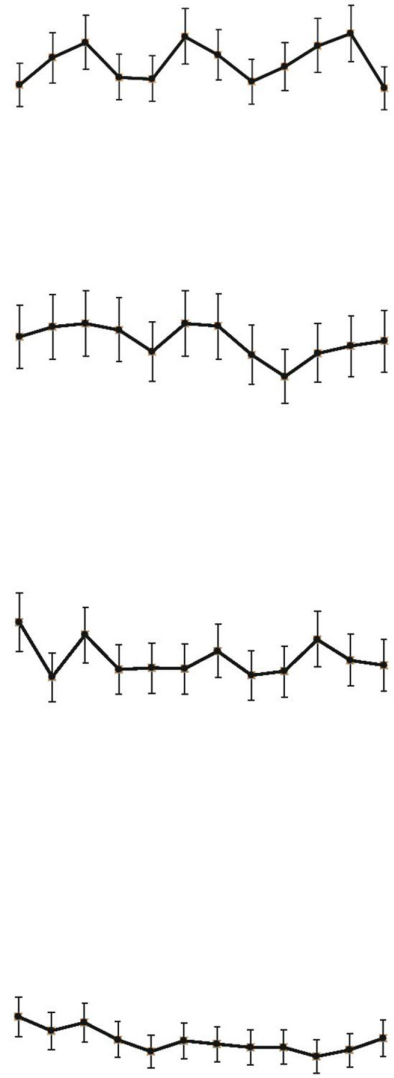

0

Figure 2 The incidence rate of type 1 diabetes by seasons (/100 000 person-years). Bar graphs show the 95\% Cls. 00-19y: 00-19 years old; 20-39y: 20-39 years old; 40-59y: 40-59 years old; 60-y: 60 years old or older. F, fall; Sp, spring; Su, summer; W, winter. 
Table 1 Tango's statistics for detecting time clustering

\begin{tabular}{lllll}
\hline & Subgroup & $\begin{array}{l}\text { Tango's } \\
\text { index } \\
\text { (measured) }\end{array}$ & $\begin{array}{l}\text { Tango's } \\
\text { index } \\
\text { (expected) }\end{array}$ & P value \\
\hline All $\quad$ - & 0.1669 & 0.1676 & 0.992 \\
& 00-19 years & 0.1702 & 0.1680 & 0.007 \\
& 20-39 years & 0.1657 & 0.1679 & 1.000 \\
& 40-59 years & 0.1674 & 0.1678 & 0.721 \\
& 260 years & 0.1685 & 0.1678 & 0.140 \\
\hline
\end{tabular}

sensitivity, specificity, positive predictive value (PPV), and negative predictive value (NPV). As mentioned above, the NDB includes more than 1000000 individuals with diabetes required.

The candidate population were patients with diabetes identified based on our definition of new type 1 diabetes. Patients were classified as having or not having type 1 diabetes based on the algorithm used in the previous study, which required that the majority of diabetes diagnosis codes are type 1 codes. ${ }^{20}$ The diagnosis codes of type 1 diabetes are shown in online supplemental table 1; other diabetic codes are shown in online supplemental tables 1 and 2.

Descriptive statistics were used to characterize the study population. We computed the sensitivity, specificity, PPV, NPV, kappa value, and Youden index for each algorithm by sex and age classes, along with the corresponding $95 \%$ CI. Sensitivity and specificity indicated the probability of each algorithm to correctly identify patients with and without type 1 diabetes, respectively. PPV indicated the proportion of patients identified by the algorithms as having type 1 diabetes who truly had a diagnosis of type 1 diabetes. NPV indicated the proportion of those identified by the algorithms as not having type 1 diabetes who truly did not have type 1 diabetes. A kappa statistic was calculated for the agreement between each algorithm and the reference standard, in order to identify the algorithm maximizing kappa (with kappa $<0$ indicating no agreement, $0-0.20$ slight agreement, $0.21-0.40$ fair agreement, 0.41-0.60 moderate agreement, 0.61-0.80 substantial agreement, and $0.81-1$ indicating almost perfect agreement). Youden index was calculated to equally weigh sensitivity and specificity using the following equation: (sensitivity+specificity) -1 .

\section{Role of the funding source}

The Japan Society for the Promotion of Science (JSPS) had no role in the study design, data collection, data analysis, data interpretation, writing of the report, or in the decision to submit the article for publication. The views and opinions expressed herein are those of the authors and do not necessarily reflect those of the JSPS. The corresponding author had full access to all the data in the study and had the final responsibility for submitting the manuscript for publication.

\section{RESULTS}

\section{Incidence rate of type 1 diabetes}

In total, 150328339 individuals (186 836905265 person-days) enrolled in the NDB used health insurances from April 1, 2013 to March 31, 2018, of whom 79173553 patients were included in this study. During the observation period (September 2014 to August 2017), 10400 patients were diagnosed with type 1 diabetes (figure 1). The incidence of type 1 diabetes from September 2014 to August 2017 was 4.42/100 000 person-years (95\% CI 4.34 to 4.51 ) (men: 4.54, $95 \%$ CI 4.41 to 4.67 ; women: $4.32,95 \%$ CI 4.21 to

Table 2 Incidence rate ratios for type 1 diabetes by season

\begin{tabular}{lllll}
\hline Variables & $\begin{array}{l}\text { Incidence rate } \\
\text { ratios }\end{array}$ & $\mathbf{9 5 \%}$ Cls & & P value \\
\hline Age $(0-19)^{\star}$ Season (spring) & 1.26 & 1.11 & 1.44 & 0.000 \\
\hline Age $(20-39)^{\star}$ Season (spring) & 1.07 & 0.94 & 1.21 & 0.305 \\
\hline Age $(40-59)^{\star}$ Season (spring) & 1.06 & 0.94 & 1.18 & 0.354 \\
\hline Age $(\geq 60)^{\star}$ Season spring) & Reference & - & - & - \\
\hline Season (spring) & 1.03 & 0.94 & 1.12 & 0.533 \\
\hline Season (others) & Reference & - & - & - \\
\hline First year of observation & 1.07 & 1.02 & 1.12 & 0.004 \\
\hline Second year of observation & 0.97 & 0.92 & 1.02 & 0.199 \\
\hline Third year of observation & Reference & - & - & - \\
\hline Age $(0-19)$ & 0.94 & 0.88 & 1.00 & 0.062 \\
\hline Age $(20-39)$ & 0.98 & 0.92 & 1.05 & 0.603 \\
\hline Age $(40-59)$ & 0.99 & 0.93 & 1.04 & 0.638 \\
\hline Age $(\geq 60)$ & Reference & - & - & - \\
\hline
\end{tabular}

$A^{*} B$ shows the interaction between $A$ and $B$. 


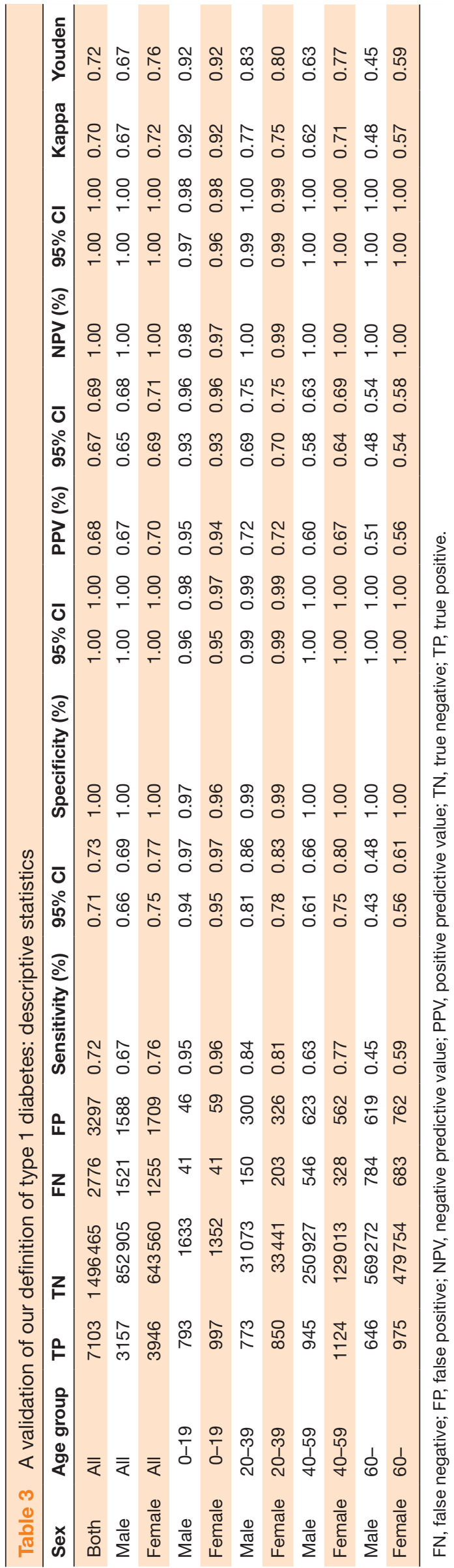

4.43). Figure 2 and online supplemental table 5 show the incidence rate of type 1 diabetes every 3 months. Among men, the incidence was highest for those aged $40-59$ years, followed by those aged $20-39$ years, $0-19$ years, and $\geq 60$ years. Among women, the incidence was highest for those aged $0-19$ years, followed by those aged $40-59$ years, $20-39$ years, and $\geq 60$ years.

\section{Time clustering and seasonality in the incidence of type 1} diabetes by age range

Tango's statistics showed no significant trend for the incidence of type 1 diabetes by season (table 1 ). However, we found a significant association between the incidence rate of type 1 diabetes and seasons for those aged $0-19$ years. As shown in figure 2 and online supplemental table 5 , the incidence rate of type 1 diabetes was higher in spring than in other seasons among those aged $0-19$ years. Table 2 shows the incidence rate ratios for type 1 diabetes. The present self-controlled case series study showed a significant interaction between spring and age $<20$ years. Individuals aged $<20$ years had a 1.26 times higher risk of type 1 diabetes in spring than in other seasons. Meanwhile, there was no significant seasonality in individuals aged $\geq 20$ years.

\section{Validation study}

In our study population, 1509641 patients met the standard of this validation study. Table 3 shows the descriptive statistics of these patients. Our definition of type 1 diabetes indicated substantial agreement with that by Schroeder $e t a l^{20}$ (Kappa statistic: 0.70, Youden statistic: 0.72 ). Thus, our definition was valid. The sensitivity and PPV were lower, as both men and women got older (from $96 \%$ to $45 \%$ ). The specificity and NPV were almost $100 \%$ at all groups. The sensitivity and PPV had very similar values, and the incidence of type 1 diabetes was similar using either our definition of diabetes or that of Schroeder et $a l^{20}{ }^{20}$ As a sensitivity analysis, we calculated the number of patients suffering from type 1 diabetes using both definitions presented in online supplemental tables 6 and 8. Figure 3 shows the number of patients suffering from type 1 diabetes by month from September 2014 to August 2017, calculated using the two definitions.

\section{DISCUSSION}

This study showed the incidence and seasonality of incidence of type 1 diabetes in Japan. The incidence was the highest in men aged 40-59 years and women aged 0-19 years. Further, we found a significant time clustering with seasonal patterns of onset of type 1 diabetes in spring (from March to May) for individuals aged under 20 years, but not for those aged $\geq 20$ years in Japan. To the best of our knowledge, this is the first study to report the nationwide incidence of type 1 diabetes.

Our findings are in contrast to previous studies that have shown no seasonality in the incidence of type 1 
The number of patients

\section{Female}

Male

with suffering type 1 diabetes by month

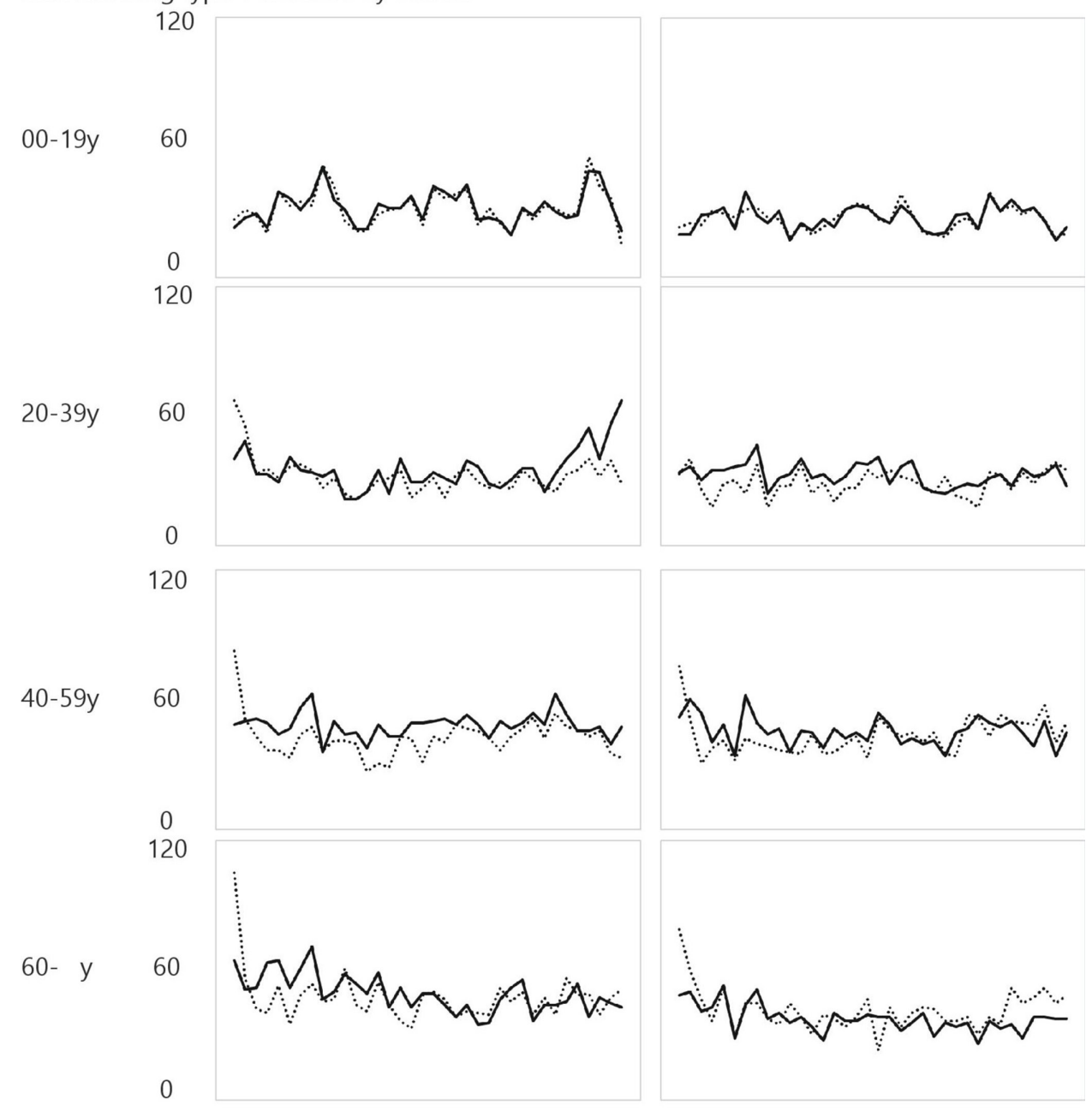

solid lines : our definition of type 1 diabetes

dotted lines: another definition of type 1 diabetes

Figure 3 Sensitivity analysis: the number of patients suffering from type 1 diabetes per month. 00-19y: 00-19 years old; 2039y: 20-39 years old; 40-59y: 40-59 years old; 60-y: 60 years old or older.

diabetes across all age ranges in countries with a lower incidence of type 1 diabetes, including Japan. ${ }^{8-10}$ Meanwhile, we found a seasonality effect in the onset of type 1 diabetes in individuals aged younger than 20 years, but not in those aged $\geq 20$ years. A previous study in China also found an age-related association between season and the incidence of type 1 diabetes. The study reported that the incidence was positively correlated with geographical latitude $(\mathrm{r}=0.88, \mathrm{p}<0.001)$ in those aged $<15$ years, but not in those aged 15 years or older. ${ }^{21}$ These results, including the interaction we showed between age ranges and seasons, may indicate that childhood-onset type 1 diabetes and adult type 1 diabetes have different modes of onset. Further descriptive epidemiological studies are needed to identify the etiology of type 1 diabetes by creating a hypothesis of the factors through descriptive epidemiological studies.

Consistent with previous findings, we found a higher incidence rate of type 1 diabetes in women aged 0-19 years than in men of the same age. Meanwhile, the incidence was higher in men aged $\geq 20$ years than in women of the same age. In addition, the incidence of type 1 diabetes was highest in men aged 40-59 years and in women aged 0-19 years. Although the incidence of type 1 diabetes was previously reported to be higher during adulthood, ${ }^{22}$ the age at which the highest incidence of type 1 diabetes differs between men and women has not been reported. Slowly progressive type 1 diabetes is also well recognized in Japan, as in many other Asian countries. Although this type of diabetes is not seen in children, a previous 
study showed that it accounts for half of all type 1 cases in adults. ${ }^{23}$ Thus, the incidence of type 1 diabetes was high in adults of that study, as patients diagnosed with slowly progressive type 1 diabetes were included.

Our study examined the best clinical diagnostic criteria for type 1 diabetes based on the opinions of clinicians, aiming to decrease the proportion of patients identified by our definition as having type 1 diabetes who truly do not have such a diagnosis. Validation studies were performed to evaluate the validity of the diagnostic criteria, and the extent of misclassification was quantified. In all groups, the kappa coefficient indicated moderate or substantial agreement (table 3, figure 3). Both PPV and sensitivity were well balanced, so that the number of patients with type 1 diabetes was similar using both diagnostic criteria at any sex and age group. For older groups, there were more misclassifications, but their impact on the incidence of type 1 diabetes was considered to be small.

A previous study in Taiwan reported that the incidence of type 1 diabetes in 2000 was 4.21, 2.93, 1.59, 2.04/100 000 person-years at the age of $0-19,20-39,40-59,60-79$ years, respectively. ${ }^{24}$ As shown in online supplemental table 5, we found a higher incidence of type 1 diabetes among patients aged $>20$ years. An underestimation of the incidence could be expected in the previous study because of Taiwan's stringent requirements to apply for a catastrophic illness certificate. As shown in figure 2, the incidence rate was small even when tabulated every 3 months. Furthermore, as shown in figure 3, our diagnostic criteria were validated.

The incidence rate of type 1 diabetes varies worldwide ${ }^{25}$ Until the early 2000 s, the worldwide incidence rate of type 1 diabetes was reported to be increasing, with reported annual increases of 2\%-5\% in Europe, the Middle East, and Australia. ${ }^{16}{ }^{26-29}$ However, our results suggest no significant trends in increases in the onset of type 1 diabetes in Japan, although this might have been affected by the short observation period of 3 years.

According to the Information Center for Specific Pediatric Chronic Diseases in Japan, 500-600 individuals aged $0-15$ years develop diabetes annually. ${ }^{30}$ In the current study, 404 (172 boys, 132 girls), 437 (170 boys, 267 girls), and 452 (199 boys, 253 girls) individuals aged 0-14 years developed type 1 diabetes during the first, second, and third year of the study period, respectively, consistent with the results of previous studies. ${ }^{8-10}$ Because we defined the patient's age according to the age at the last use of insurance from September 2017 to March 2018, patients aged 12-15 years were included in the age group of 15 years and older. As shown in online supplemental table 6, 1895 patients aged 0-19 years developed type 1 diabetes within the 3 -year study period, consistent with the findings that $500-600$ patients aged $0-15$ years develop diabetes annually. ${ }^{31}$

The strengths of the study include the high generalizability of the results, as we used all data available on the NDB. Moreover, using the NDB allowed us to include a sample cohort with minimal selection bias ${ }^{15}$ and to include all patients with type 1 diabetes. The incidence rate has important implications in both clinical and public health policy. However, it would be prohibitive to conduct a randomized controlled trial or prospective cohort study for an in-depth investigation of the role of a specific risk factor in the etiology of a disease because such a study would be too large and expensive.

Meanwhile, this study had several limitations. First, we defined patients with type 1 diabetes in the NDB as those recognized of having any of the type 1 diabetes diagnosis codes, who were prescribed medication for type 1 diabetes (insulin), and who had medical examinations codes about self-monitoring of blood glucose as patients with type 1 diabetes. In the validation study, our definition was considered to be valid and consistent with Japanese diabetes clinical practice. We did not include patients who were not treated with self-monitoring of blood glucose. However, since only very few patients do not self-monitor their blood glucose after the onset of type 1 diabetes, our patient selection procedure was appropriate. Second, the NDB does not include any laboratory data, such as plasma glucose levels. Thus, we could not confirm the levels of blood glucose, hemoglobin A1c, or any types of antibodies, such as antiglutamic acid decarboxylase antibody, when type 1 diabetes occurred. As an alternative indicator, we defined the condition of type 1 diabetes in the NDB using codes, and the number of children with type 1 diabetes was similar to that in a previous report. ${ }^{30}$ Third, we could not review the medical data (eg, body weight, smoking history, and family history) of each patient in detail. Although timeindependent confounders (eg, genetic factors) or unmeasured confounders can be adjusted in a self-controlled case series study design, it remains an observational study. Further, the confounders cannot be completely adjusted. Fourth, the health check-ups performed at schools usually occur in April and May, which could have affected the results. If our result that the incidence of type 1 diabetes is higher in spring was only affected by the health check-up period, the incidence in March should have been lower than that in April and May. However, as seen in online supplemental table 6 , this was not the case. Finally, we selected individuals who used their insurance before and after the observation period. Although we considered our definition reasonable, we cannot exclude the possibility of overestimating the incidence of type 1 diabetes.

In conclusion, the incidence of type 1 diabetes is highest among Japanese men aged 40-59 years and Japanese women aged 0-19 years. In addition, we found that the incidence of younger-onset diabetes increases in spring (from March to May). This descriptive epidemiological study can help clarify the etiology of type 1 diabetes.

Acknowledgements We would like to thank Editage (www.editage.com) for English Language editing.

Contributors YN conducted the study design, analysis, and discussion. SO evaluated the results from the viewpoint of a clinician. TN provided advice on the 
study design and discussed the findings from the viewpoint of an epidemiologist. TM, SK, and TH performed the initial NDB analysis and provided technical advice. $\mathrm{HI}$ evaluated the results from the viewpoint of a clinician. TI provided advice on the study design and discussed the findings from the viewpoint of public health. Guarantor: YN.

Funding The present study was supported by JSPS KAKENHI Grant Number JP18K17390 and JP18H04126.

Competing interests YN reports receiving consultant fees from Novo Nordisk. SO reports receiving lecturer's fees from Novo Nordisk, Mitsubishi Tanabe, Sumitomo Dainippon, MSD, Bayer, Eli Lilly, Boehringer Ingelheim, Ono, AstraZeneca, Sanofi, Takeda, and ARKRAY. HI reports receiving lecture fees and consultant fees from Takeda, Eli Lilly Japan, Sanofi, Merck \& Co., Astellas, Mitsubishi Tanabe, Daiichi Sankyo, Ono, AstraZeneca, Taisho Toyama, Shionogi, Kowa, Boehringer Ingelheim, Novo Nordisk, Sumitomo Dainippon, and Kyowa Hakko Kirin. No other potential conflicts of interest relevant to this article are reported.

Patient consent for publication Obtained.

Ethics approval The study was approved by the Ethics Committee of Nara Medical University (1123-5).

Provenance and peer review Not commissioned; externally peer reviewed.

Data availlability statement No data are available. Guidelines do not allow access to NDB except for those permitted.

Supplemental material This content has been supplied by the author(s). It has not been vetted by BMJ Publishing Group Limited (BMJ) and may not have been peer-reviewed. Any opinions or recommendations discussed are solely those of the author(s) and are not endorsed by BMJ. BMJ disclaims all liability and responsibility arising from any reliance placed on the content. Where the content includes any translated material, BMJ does not warrant the accuracy and reliability of the translations (including but not limited to local regulations, clinical guidelines, terminology, drug names and drug dosages), and is not responsible for any error and/or omissions arising from translation and adaptation or otherwise.

Open access This is an open access article distributed in accordance with the Creative Commons Attribution Non Commercial (CC BY-NC 4.0) license, which permits others to distribute, remix, adapt, build upon this work non-commercially, and license their derivative works on different terms, provided the original work is properly cited, appropriate credit is given, any changes made indicated, and the use is non-commercial. See: http://creativecommons.org/licenses/by-nc/4.0/.

ORCID iD

Tatsuya Noda http://orcid.org/0000-0002-3652-7547

\section{REFERENCES}

1 Kerner W, Brückel J, Definition GDA, German Diabetes Association. Definition, classification and diagnosis of diabetes mellitus. Exp Clin Endocrinol Diabetes 2014;122:384-6.

2 Green A, Gale EA, Patterson CC. Incidence of childhood-onset insulin-dependent diabetes mellitus: the EURODIAB ACE study. Lancet 1992;339:905-9.

3 Xia Y, Xie Z, Huang G, et al. Incidence and trend of type 1 diabetes and the underlying environmental determinants. Diabetes Metab Res Rev 2019;35:e3075.

4 Szypowska A, Ramotowska A, Wysocka-Mincewicz M, et al. Seasonal variation in month of diagnosis of Polish children with type 1 diabetes - a multicenter study. Exp Clin Endocrinol Diabetes 2019;127:331-5.

5 Moltchanova EV, Schreier N, Lammi N, et al. Seasonal variation of diagnosis of type 1 diabetes mellitus in children worldwide. Diabet Med 2009;26:673-8.

6 Willis JA, Scott RS, Darlow BA, et al. Seasonality of birth and onset of clinical disease in children and adolescents (0-19 years) with type 1 diabetes mellitus in Canterbury, New Zealand. $J$ Pediatr Endocrinol Metab 2002;15:645-7.

7 Mooney JA, Helms PJ, Jolliffe IT, et al. Seasonality of type 1 diabetes mellitus in children and its modification by weekends and holidays: retrospective observational study. Arch Dis Child 2004;89:970-3.
8 Onda Y, Sugihara S, Ogata T, et al. Incidence and prevalence of childhood-onset type 1 diabetes in Japan: the T1D study. Diabet Med 2017;34:909-15.

9 Shamis I, Gordon O, Albag Y, et al. Ethnic differences in the incidence of childhood IDDM in Israel (1965-1993). marked increase since 1985, especially in Yemenite Jews. Diabetes Care 1997;20:504-8.

10 Ye J, Chen RG, Ashkenazi I, et al. Lack of seasonality in the month of onset of childhood IDDM (0.7-15 years) in Shanghai, China. J Pediatr Endocrinol Metab 1998:11:461-4.

11 Sugiyama T, Imai K, Ihana-Sugiyama N, et al. Variation in process quality measures of diabetes care by region and institution in Japan during 2015-2016: an observational study of nationwide claims data. Diabetes Res Clin Pract 2019;155:107750.

12 Hayashi S, Noda T, Kubo S, et al. Data regarding fracture incidence according to fracture site, month, and age group obtained from the large public health insurance claim database in Japan. Data Brief 2019;23:103780.

13 Hayashi S, Noda T, Kubo S, et al. Variation in fracture risk by season and weather: a comprehensive analysis across age and fracture site using a national database of health insurance claims in Japan. Bone 2019;120:512-8.

14 Okumura Y, Sugiyama N, Noda T, et al. Psychiatric admissions and length of stay during fiscal years 2014 and 2015 in Japan: a retrospective cohort study using a nationwide claims database. $J$ Epidemiol 2019;29:288-94.

15 Kubo S, Noda T, Myojin T, et al. National database of health insurance claims and specific health checkups of Japan (NDB): outline and patient-matching technique, 2018. Available: https://doi. org/ [Accessed 01 Apr 2018].

16 Patterson CC, Dahlquist GG, Gyürüs E, et al. Incidence trends for childhood type 1 diabetes in Europe during 1989-2003 and predicted new cases 2005-20: a multicentre prospective registration study. Lancet 2009;373:2027-33.

17 Tango T. Asymptotic distribution of an index for disease clustering. Biometrics 1990;46:351-7.

18 Whitaker HJ, Farrington CP, Spiessens B, et al. Tutorial in biostatistics: the self-controlled case series method. Stat Med 2006;25:1768-97.

19 Farrington CP. Relative incidence estimation from case series for vaccine safety evaluation. Biometrics 1995;51:228-35.

20 Schroeder EB, Donahoo WT, Goodrich GK, et al. Validation of an algorithm for identifying type 1 diabetes in adults based on electronic health record data. Pharmacoepidemiol Drug Saf 2018:27:1053-9.

21 Weng J, Zhou Z, Guo L, et al. Incidence of type 1 diabetes in China, 2010-13: population based study. BMJ 2018;360:j5295.

22 Thomas NJ, Jones SE, Weedon MN, et al. Frequency and phenotype of type 1 diabetes in the first six decades of life: a cross-sectional, genetically stratified survival analysis from UK Biobank. Lancet Diabetes Endocrinol 2018;6:122-9.

23 Cockram CS. The epidemiology of diabetes mellitus in the AsiaPacific region. Hong Kong Med J 2000;6:43-52.

24 Jiang Y-D, Chang C-H, Tai T-Y, et al. Incidence and prevalence rates of diabetes mellitus in Taiwan: analysis of the 2000-2009 nationwide health insurance database. J Formos Med Assoc 2012;111:599-604.

25 Mayer-Davis EJ, Kahkoska AR, Jefferies C, et al. ISPAD clinical practice consensus guidelines 2018: definition, epidemiology, and classification of diabetes in children and adolescents. Pediatr Diabetes 2018;19:7-19.

26 Harjutsalo V, Sund R, Knip M, et al. Incidence of type 1 diabetes in Finland. JAMA 2013;310:427-8.

27 Tuomilehto J. The emerging global epidemic of type 1 diabetes. Curr Diab Rep 2013;13:795-804.

28 Mamoulakis D, Galanakis E, Bicouvarakis S, et al. Epidemiology of childhood type I diabetes in Crete, 1990-2001. Acta Paediatr 2003;92:737-9

29 Karvonen M, Pitkäniemi J, Tuomilehto J. The onset age of type 1 diabetes in Finnish children has become younger. The Finnish childhood diabetes registry group. Diabetes Care 1999;22:1066-70.

30 Available: https://www.jma.go.jp/jma/indexe.html [Accessed 21 Dec 2019].

31 Available: https://www.ncchd.go.jp/en/center/activity/diseases/ [Accessed 21 Dec 2019]. 